\title{
DETECTION OF THE SHORTEST ROBOT TRAJECTORY BY GENETIC ALGORITHMS
}

\author{
SCHREIBER, P.\& TANUSKA, P.
}

Abstract: Genetic algorithms for optimal trajectory estimation between two points of robot's working space are described in this article. The length of trajectory is used as one of possible criteria. Genetic algorithms can be used in base form and the computations can be done in 3D-working space without transformation into C-space. Genetic algorithm in the $3 D$ - space without constraints is discussed in the first part of contribution. Base terms like chromosome, objective function, genetic operations etc. are described with reference to solved problem. Necessary supplements of algorithm (the way of points generation, changes in genetic operations) for solution of collisions with constraints are given in the second part of article, too.

Key words: Genetic algorithms, robot systems, trajectory, collision, optimization
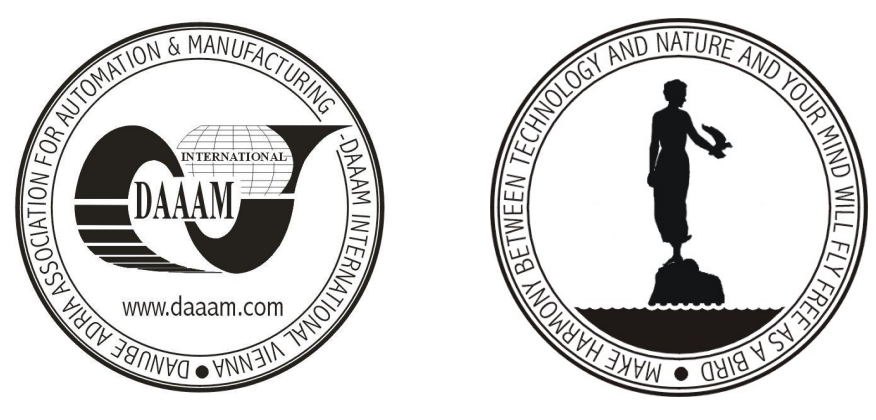

Authors' data: Doc. Ing. PhD. Schreiber, P[eter]; Doc. Ing. PhD. Tanuska, P[avol], Slovak University of technology, Faculty of Material Science and Technology in Trnava,Trnava, Slovakia, peter.schreiber@stuba.sk, pavol.tanuska@stuba.sk

This Publication has to be referred as: Schreiber, P. \& Tanuska, P. (2007). Detection of the shortest robot trajectory by genetic algorithms, Chapter 18 in DAAAM International Scientific Book 2007, B. Katalinic (Ed.), Published by DAAAM International, ISBN 3-901509-60-7, ISSN 1726-9687, Vienna, Austria DOI: $10.2507 /$ daaam.scibook.2007.18 